\title{
An inversion method based on multi-angular approaches for estimating bare soil surface parameters from RADARSAT-1
}

\author{
M. R. Sahebi ${ }^{1}$ and J. Angles ${ }^{2}$ \\ ${ }^{1}$ Geomatics Engineering Faculty, K. N. Toosi University of Technology, Tehran, Iran \\ ${ }^{2}$ VEGA Technologies - Finmeccanica Group, Toulouse, France
}

Received: 4 November 2008 - Published in Hydrol. Earth Syst. Sci. Discuss.: 7 January 2009

Revised: 12 November 2010 - Accepted: 16 November 2010 - Published: 30 November 2010

\begin{abstract}
The radar signal recorded by earth observation (EO) satellites is sensitive to soil moisture and surface roughness, which both influence the onset of runoff.

This paper focuses on inversion of these parameters using a multi-angular approach based on RADARSAT-1 data with incidence angles of $35^{\circ}$ and $47^{\circ}$ (in mode S3 and S7). This inversion was performed with three backscatter models: Geometrical Optics Model (GOM), Oh Model (OM), and Modified Dubois Model (MDM), which were compared to obtain the best configuration. Mean absolute errors of 1.23, 1.12, and $2.08 \mathrm{~cm}$ for roughness expressed in rms height and for dielectric constant, mean absolute errors of 2.46 - equal to $3.88\left(\mathrm{~m}^{3} \mathrm{~m}^{-3}\right)$ in volumetric soil moisture, -4.95 - equal to $8.72\left(\mathrm{~m}^{3} \mathrm{~m}^{-3}\right)$ in volumetric soil moisture - and 3.31 equal to $6.03\left(\mathrm{~m}^{3} \mathrm{~m}^{-3}\right)$ in volumetric soil moisture - were obtained for the MDM, GOM, and OM simulation, respectively. These results indicate that the MDM provided the most accurate data with minimum errors. Therefore, the latter inversion algorithm was applied to images, and the final results are presented in two different maps showing pixel and homogeneous zones for surface roughness and soil moisture.
\end{abstract}

\section{Introduction}

A multi-technique approach using Synthetic Aperture Radars (SAR) data is considered essential for many environmental studies. For the scope of this paper, land surface parameters were monitored through estimation of soil surface roughness and moisture status over a large area. Mapping of soil surface roughness and moisture over a large scale at regular intervals or at critical times (e.g., floods, droughts, landslides) is useful for both agronomists and hydrologists.

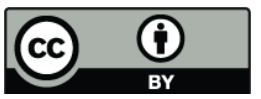

Correspondence to: M. R. Sahebi (sahebi@kntu.ac.ir)
Such maps provide an overall view of land surface parameters on a spatial scale, which allow for the detection of dry, wet, smooth, or rough areas and the identification of areas with potential hydrological or agronomic problems. However, soil moisture and soil surface roughness both influence radar backscatter. Moreover, separation of moisture from roughness on the radar signal over bare soils is critical.

SARs are active microwave sensors with the capability of acquiring data under almost all meteorological conditions without an external source of illumination. Therefore, information can be collected on a regular basis over an area covered with clouds at either day or night. This advantage over sensors operating in the visible and infrared portion of the electromagnetic spectrum improves the capability for monitoring dynamic phenomena. The potential for SAR data has been demonstrated for monitoring the Earth's surface (Ulaby et al., 1978, 1982, 1996; Dobson and Ulaby, 1986a,b; Engman and Wang, 1987; Oh et al., 1992; Fung and Chen, 1992; Fung, 1994; Dubois et al., 1995). In this regard, several researchers interested in data collection with global coverage at regular time intervals may prefer spaceborne platforms (Wagner et al., 2007).

Separation of land cover information using a single channel of SAR data can be difficult. Furthermore, the parameterization of surface moisture can pose major problems for characterizing soil surface roughness and vice versa (Baghdadi et al., 2004; Verhoest et al., 2008)

Soil surface radar response can be significantly influenced by the following parameter categories: (1) target parameters, such as moisture, roughness, and vegetation cover (if present) and (2) sensor parameters, such as frequency, polarization, and incidence angle. The sensor parameters are typically known in remote sensing applications; however, the relationship between the target and measured signals must be investigated. Estimation of soil surface parameters is usually obtained using theoretical or empirical relationships to convert the measured backscatter coefficient $\left(\sigma^{0}\right)$ into soil

Published by Copernicus Publications on behalf of the European Geosciences Union. 
surface roughness and moisture (Dobson and Ulaby, 1986a; Prévot et al., 1993; Ulaby et al., 1996). Thus, there was one equation with two unknowns for each target or three if the model incorporates the correlation length. Consequentially, the use of radar data acquired with a single configuration does not generally allow for the estimation of these soil surface variables. Therefore, multi-technique concepts (multipolarization, multi-angular, multi-sensor, multi-frequency, and multi-temporal) are the primary solution.

Colpitts (1998) combined more than two images with different incidence angles to separate the effects of soil surface roughness and soil moisture for several tillage types. Pasquariello et al. (1997) and Baghdadi et al. (2002) also determined that soil moisture estimation could be improved by using IEM inversion with multi-angular SAR imagery configuration. Based on a theoretical analysis, Fung et al. (1996) reported that the multi-angular approach could be used to determine roughness parameters for IEM model and is also preferred over direct ground measurements in certain cases.

Zribi and Dechambre (2002) defined the Z-index, which is a ratio of RMS height and correlation length, from backscattering coefficient differences generated by the IEM model with two different incidence angles. This index was only proportional to soil surface roughness. Based on this study, Rahman et al. (2008) demonstrated that the RMS height and correlation length could be derived separately from the Z-index using the IEM with a SAR image acquired under dry soil conditions. The approach requires the use of multi-angular SAR image acquisition (Verhoest et al., 2008).

Based on simulation results, Sahebi et al. $(2001,2002)$ indicated that a multi-angular approach is better adapted for the separation of moisture and roughness signals than multipolarization and multi-frequency approaches. Therefore, the Radarsat-1 satellite, which is capable of acquiring data at different incidence angles, can be used to estimate soil moisture and surface roughness. However, development of a method adapted to RADARSAT- 1 data for estimation of these parameters is critical.

Mapping of surface characteristics can be performed either from point measurements or from estimated values from models and remote sensing. Soil moisture from microwave remote sensing instruments can be derived by converting the detected dielectric constant into volumetric moisture content. The accuracy of remote sensing data depends on sensor resolution and the algorithms or models applied to the signal to obtain soil moisture or roughness estimate. These results in information on spatial variability (Benallegue et al., 1998), and the derived values provide a map of the area without interpolating data as with point measurements.

The objective of this paper is to propose an algorithm to retrieve soil surface parameters from two or three SAR images with different incidence angles (multi angular configuration). Therefore, a transformation approach is formulated and defined to solve the inverse problem for the operational retrieval and mapping of soil surface roughness and moisture.
The strategy consists of formulating the inverse problem in the context of multi-angular RADARSAT-1 data. We investigated the relationship between the C-band radar response and soil parameters, specifically the soil dielectric constant $(\varepsilon)$ and rms height $(s)$, which are used to constrain target parameters in the Geometrical Optics Model (GOM) (Ulaby et al., 1982), the Oh Model (OM) (Oh et al., 1992), and the Modified Dubois Model (MDM) (Angles, 2001). Based on results obtained with MDM, a roughness and moisture map for the Chateauguay watershed (Quebec, Canada) was produced.

\section{Study site and data description}

The agricultural site chosen for this study is part of the Chateauguay watershed $\left(73^{\circ} 46^{\prime} \mathrm{W}, 45^{\circ} 19^{\prime} \mathrm{N}\right)$ located on the south shore of the St. Lawrence River and southwest of Montreal, Canada (Fig. 1). This area consists primarily of agricultural fields on a rather flat relief plateau with homogeneous texture comprised of approximately $36 \%$ clay, $42 \%$ silt, and $22 \%$ sand. During ground surveys, the parcel surfaces were determined as rough to very rough.

Roughness and moisture measurements were performed simultaneously for 27 agricultural parcels with image acquisitions (Fig. 2). Roughness measurements were determined using a homemade needle profilometer with a length of 2 m. For calculation of RMS height, six $2 \mathrm{~m}$ long $(1.5 \mathrm{~cm}$ sampling interval) surface profiles (three parallel and three perpendicular to the soil furrows) were investigated for each parcel. These profiles were photographed and then digitized. The method for extracting and modeling roughness parameters, such as rms height and correlation length, has been described in detail by Beaulieu et al. (1995). However, this method introduces some errors that affect roughness estimation, which may be caused by different sources, such as the discretization interval and profilometer resolution (Mattia et al., 2003, 2006). Verhoest et al. (2008) presented a detailed review on different sources of the error.

Soil surface moisture measurements were performed with a Thetaprobe soil moisture sensor based on the time domain reflectometry (TDR) (Delta Devices Ltd., 1996) concept. The measurements reflect moisture in the $0-5 \mathrm{~cm}$ depth corresponding to the length of the Thetaprobe needles. A total of 15 samples were collected for each land parcel. The direct outputs (DC voltage in $\mathrm{V}$ ) were converted to both volumetric soil moisture content $\left(\mathrm{m}^{3} \mathrm{~m}^{-3}\right)$ and dielectric constant using the equation presented in the Thetaprobe Soil Moisture User Manual (Delta Devices Ltd., 1996). The final results are presented for both soil moisture content and dielectric constant. Additionally, five $0-5 \mathrm{~cm}$ soil samples for each parcel were transferred to our laboratory to evaluate the results obtained with this method. Wet and dry weights were used to determine gravimetric and volumetric soil moisture content. The soil moisture contents $\left(\mathrm{m}^{3} \mathrm{~m}^{-3}\right)$ obtained by these two methods were compared, and a volumetric soil moisture 


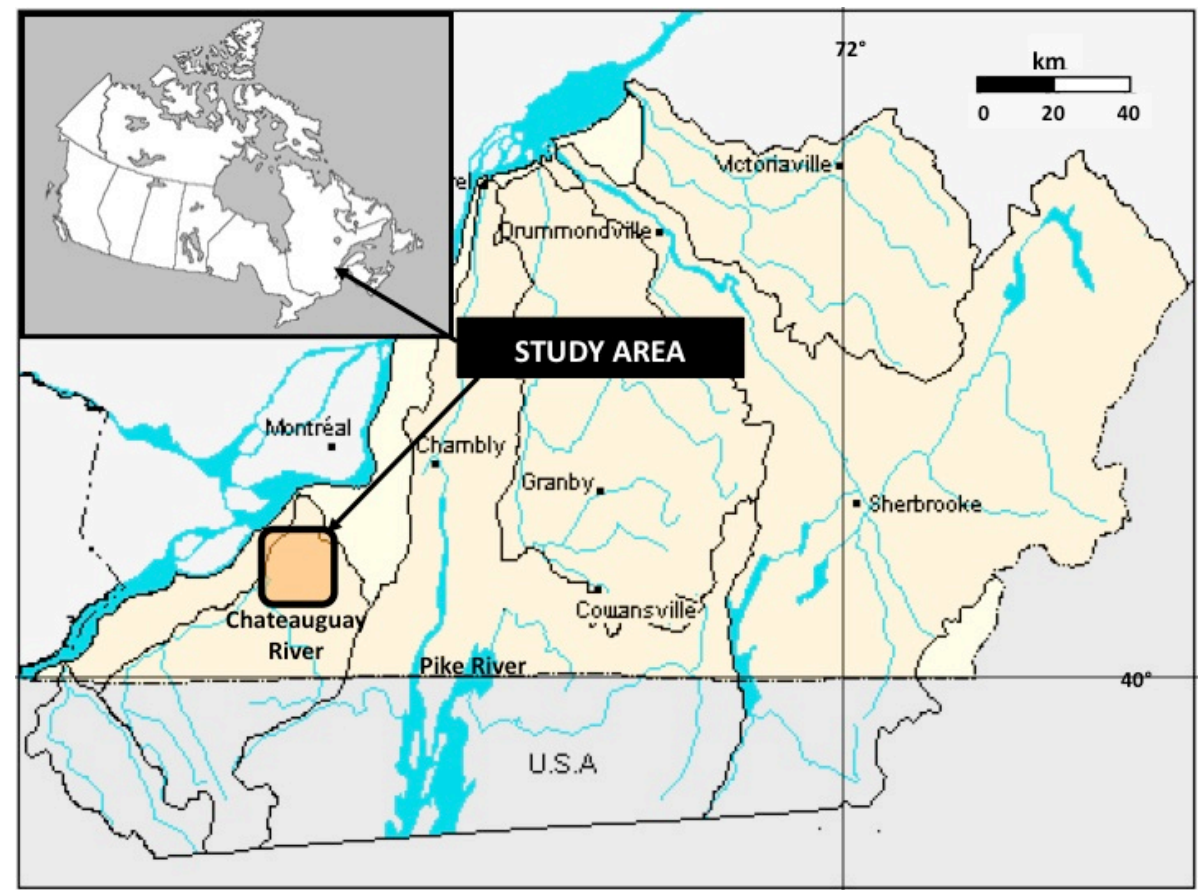

Fig. 1. Location of study area.

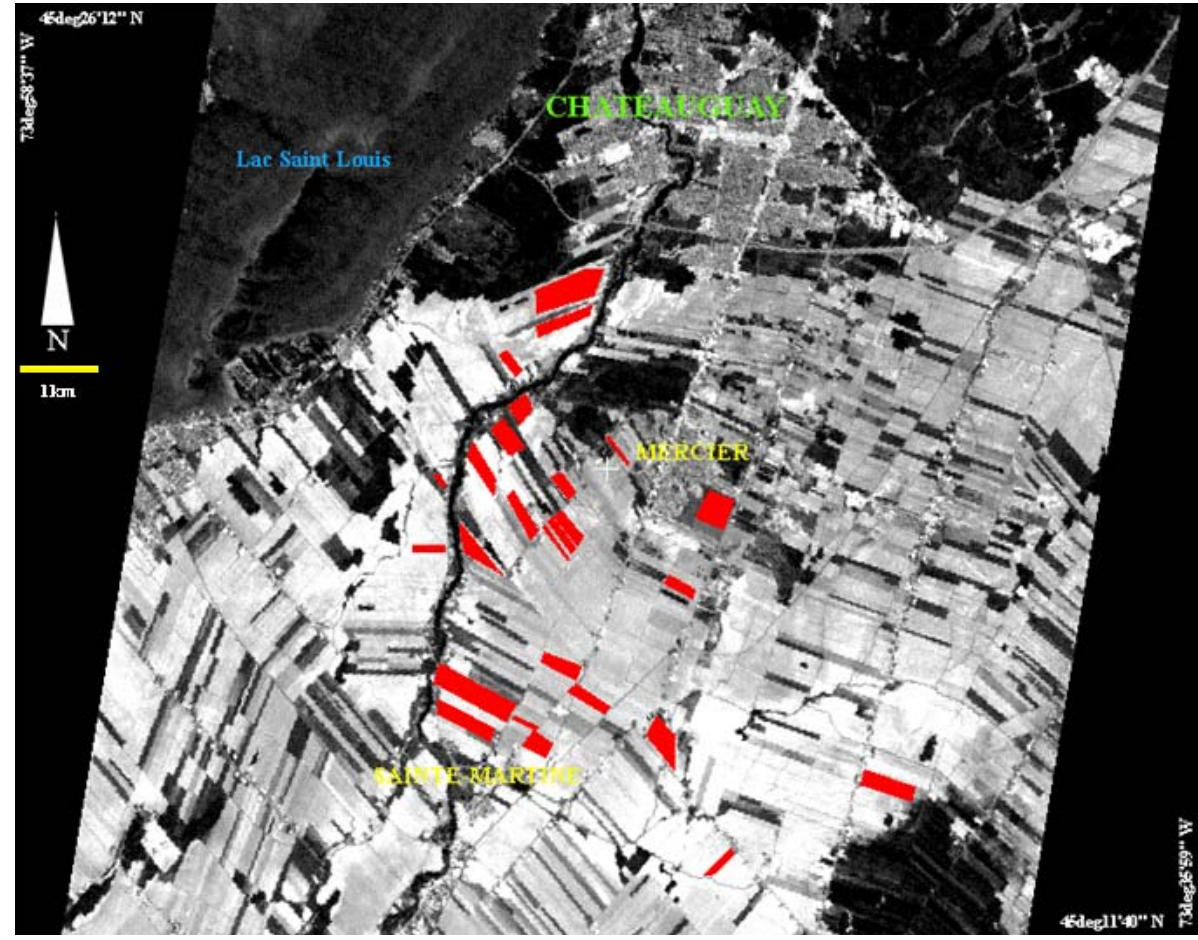

Fig. 2. Location of the parcels (Airborne photography over Chateauguay watershed).

difference of $1.8 \%$ was observed between the two methods. The exact position of each in-situ measurement was registered by GPS.
The satellite data used in this study correspond to a RADARSAT-1 image pair. The first image was acquired on 15 November 1999 in S3 (Standard-3) mode with incidence angles ranging from 30 to $35^{\circ}$, and the second 
image was acquired on 18 November 1999 in S7 (Standard7) mode with incidence angles ranging from 45 to $49^{\circ}$. The third image was acquired on 12 November 1999 in S1 (Standard-1) mode with incidence angle ranging from 20 to $25^{\circ}$. Notably, the third image was used only for GOM. The RADARSAT DN values were converted to the backscattering coefficient $\left(\sigma^{0}\right)$ according to Shepard (1998). An average $\sigma^{0}(\mathrm{~dB})$ was assigned to each parcel (approximately 20 to 30 pixels) to include the spatial variability and avoid problems related to georeferencing of individual pixels of the parcels in the study area (homogeneous soil structure, bare soil, homogeneous ploughing). The surface roughness and moisture were measured in-situ on 15 and 18 November (the same dates as the satellite image acquisitions). Between the periods of data acquisition, the weather was stable and surface moisture had not changed significantly because of the low evaporation and temperature at that time of the year. According to local observations and Environment Canada, average daily temperatures were $2.3{ }^{\circ} \mathrm{C}$ (with a minimum value of $1.5^{\circ}$ and a maximum value of $7^{\circ}$ ), and there was no recorded rainfall or ground frost between the two acquisition dates. However, 20 parcels were selected with nearly the same moisture and roughness for the two dates to completely satisfy the conditions of this study. Therefore, the difference between the measurements on the two days for soil moisture and soil roughness were less than $8 \%$ and $5 \%$, respectively.

\section{Methodology}

As mentioned previously, soil moisture and soil surface roughness were estimated from SAR images based on an inversion algorithm. Estimation of soil moisture and soil surface roughness can be achieved using the inversion of theoretical or empirical methods, and the relationship to the measured backscatter coefficient from images was converted into soil surface parameters. At least two equations are required because there was more than one unknown parameter, such as the dielectric constant and RMS height, which can be provided by multi-technique algorithms.

A previous ground based experiment (Chanzy et al., 1998; Baghdadi et al., 2006; Rahman et al., 2007) and theoretical study (Sahebi et al., 2001, 2002; Fung et al., 1996) demonstrated that the multi-angular configuration is the best for estimation of bare soil surface parameters. Therefore, the multi-angular configuration was used for the inversion of backscattering models to estimate roughness and soil moisture from RADARSAT-1 data acquired at two different incidence angles. This approach was tested with different RADARSAT-1 images acquired at different incidence angles (between 20 and $49^{\circ}$ ), and the images presented herein yielded the best results.

\subsection{Model descriptions}

As previously discussed, the aim of this study was to estimate bare soil surface parameters using multi-angular approaches. This process was performed using existing theoretical and empirical backscatter models that introduce the relationship between backscatter coefficient and surface parameters (roughness and dielectric constant).

The comparison of the mentioned backscattering models was performed using simulations by GOM (Geometrical Optics Model; Ulaby et al., 1982), OM (Oh Model; Oh et al., 1992), and MDM (Modified Dubois Model; Angles, 2001), since this study site profile contains very rough surfaces. Other models, such as IEM (Fung, 1994) and SPM (Ulaby et al., 1982), could not be used in this study because of the incompatibility between the validity range of the models and study area conditions.

\subsubsection{Geometrical Optics Model (GOM)}

The Geometrical Optics Model (GOM), which is also known as the Kirchhoff method, under the stationary phase approximation is intended to express scattering by rough surfaces with $0.06 k^{2} \ell^{2}>k s, k \ell>6$ and $2 k s \cos \theta^{2}>10$, where $\ell$ is the correlation length, $k$ is the wave number $(k=2 \pi / \lambda$, where $\lambda$ is the wavelength), $s$ is the root mean square (RMS heights), and $\theta$ is the incidence angle. This model predicts that $\sigma_{\mathrm{hh}}^{0}(\theta)=\sigma_{\mathrm{vv}}^{0}(\theta)$ at all incidence angles of the radar signal. The expression for the co-polarized backscattering coefficient is given by:

$\sigma_{\mathrm{pp}}^{0}(\theta)=\left[\frac{\left|R_{\mathrm{pp}}(0)\right|^{2}}{\left(2 \mathrm{~m}^{2} \cos ^{4} \theta\right)}\right] \times \exp \left(\frac{\tan ^{2} \theta}{2 \mathrm{~m}^{2}}\right)$

where $R_{\mathrm{pp}}(0)$ is the surface reflectivity from normal incidence, and $\mathrm{m}$ is the rms slope of the surface and is equal to $\sqrt{ } 2 s / \ell$ and $s / \ell$ for Gaussian and exponential functions, respectively (Oh et al., 1992). According to Oh et al. (1992), the exponential function is adapted to smooth surfaces and the Gaussian autocorrelation function is adapted to rough surfaces. Based on the study area descriptions (rough to very rough surfaces), the Gaussian autocorrelation function was chosen for calculating $\mathrm{m}$ values.

\subsubsection{Oh Model (OM)}

Oh et al. (1992) developed an empirical model based on experimental data acquired in L-, C-, and X-bands (1.5, 4.75, and $9.5 \mathrm{GHz}$ respectively) because of the inadequate performance of theoretical models for predicting the backscatter response of random surfaces. This model was designed for surfaces with various moisture conditions and roughness from slightly smooth to very rough and does not incorporate the correlation length. The valid surface conditions cover the following ranges: $0.1<k s<6.0,2.6<k \ell<19.7$ and $9 \%<m_{\mathrm{v}}<31 \%$, where $m_{\mathrm{v}}$ is the volumetric soil moisture. 
The backscattering coefficients in $\mathrm{HH}$ polarization for this model can be expressed by:

$\sigma_{\mathrm{hh}}^{0}=g \sqrt{p} \cos ^{3} \theta\left[\Gamma_{\mathrm{v}}(\theta)+\Gamma_{\mathrm{h}}(\theta)\right]$

where

$$
\begin{aligned}
& \sqrt{p}=1-\left(\frac{2 \theta}{\pi}\right)^{\left.\left[1 / 3 \Gamma_{0}\right)\right]} \times \exp (-k s), \\
& g=0.7\left[1-\exp \left(-0.65(k s)^{1.8}\right)\right]
\end{aligned}
$$

and $\Gamma_{0}$ is the Fresnel reflectivity of surface at nadir. $\Gamma_{\mathrm{v}}$ and $\Gamma_{\mathrm{h}}$ are the Fresnel reflection coefficients for horizontal and vertical polarization, respectively. Correlation length effect is not included.

\subsubsection{Modified Dubois Model (MDM)}

The empirical model developed by Dubois et al. (1995) was initially developed to separate moisture and roughness using a bipolarization approach. This model is limited to $k s \leq 2.5$, $\theta \geq 30^{\circ}$, and moisture contents $m_{\mathrm{v}} \leq 35 \%$. This model was tested over the study area by researchers at Université de Sherbrooke (Angles, 2001), and the results demonstrated an important difference between simulated and measured values of moisture and roughness. The method that Dubois et al. (1995) followed was used to adapt the Dubois model to measured data over the Quebec agricultural area. This case was comprised of two agriculture sites that included more than 40 observed fields. One site with more than 25 fields was selected for model development, and the other site was used for validation and calibration. A total of 10 different RADARSAT-1 images (C-band, HH-polarized and incidence angles between $20^{\circ}$ and $50^{\circ}$ ) and measured ground data (soil surface roughness, soil moisture, and soil texture) were used to overcome this discrepancy. The images were corrected geometrically and the backscattering coefficients of the bare soils were then extracted. The same methods presented by Dubois et al. (1995) were followed exactly, and the constant parameters were recalculated. The obtained results demonstrate an improvement of $5.65 \mathrm{~dB}$ (equivalent to $43 \%$ ) for the $\mathrm{S} 1$ image mode, $2.32 \mathrm{~dB}$ (equivalent to $17 \%$ ) for the $\mathrm{S} 3 \mathrm{im}$ age mode, and $0.3 \mathrm{~dB}$ (equivalent to $2 \%$ ) for the S7 image mode.

This modification is presented as a new model referred to as the Modified Dubois Model (MDM). MDM expresses the backscattering coefficient for this model and is described by Eq. (3) that can be applied to bare agricultural surfaces in Quebec with $1 \mathrm{~cm}<s<6 \mathrm{~cm}$ and $14 \%<m_{\mathrm{v}}<32 \%$ (Angles, 2001).

$$
\begin{aligned}
& \sigma_{\text {hh }}^{0}=10^{-3.67} \times \frac{\cos ^{1.5} \theta}{\sin ^{5} \theta} \times 10^{0.112 \tan \theta \varepsilon} \\
& \times(k s . \sin \theta)^{0.883} \times \lambda^{0.7}
\end{aligned}
$$

where $k$ is the wave number $(k=2 \pi / \lambda)$ and $\lambda$ is the wavelength.

Applying this model to RADARSAT- 1 data acquired at two different incidence angles of the same target with a short time interval, this approach generates a two equation system with two unknowns, which can be resolved to obtain $s$ and $\varepsilon$. However, this model should be tested in other regions with different conditions for validation purposes.

\section{Inversion method}

\subsection{Method description}

If backscatter coefficient ( $\sigma_{\mathrm{hh}}^{0}$ in this case) measurements for a given surface at the incidence angles $\theta_{1}, \theta_{2}$ and $\theta_{3}$ (if applicable) are available, then the land-surface parameters, which are the same in all images, can be computed by inverting the above models.

As previously explained, three models were chosen. The MDM is analytically invertible. Equations (4) and (5) show the inversion of this model to calculate land-surface parameters using the multi-angular approach for hh-polarization:

$$
\begin{aligned}
& \varepsilon_{\mathrm{r}}=\frac{\log [A]}{0.112 \times\left(\tan \theta_{1}-\tan \theta_{2}\right)} \\
& s=\frac{1}{k} \times \\
& 0.883 \sqrt{10^{3.67} \times \sigma_{\mathrm{hh}}^{0}\left(\theta_{1}\right) \times \frac{\sin ^{4.117}\left(\theta_{1}\right)}{\cos ^{1.5}\left(\theta_{2}\right)} \times A^{-\left(\frac{\tan \left(\theta_{1}\right)}{\tan \left(\theta_{1}\right)-\tan \left(\theta_{2}\right)}\right)} \times \lambda^{-0.7}}
\end{aligned}
$$

wher $\sigma_{\text {hh }}^{0}\left(\theta_{1}\right)$ and $\sigma_{\text {hh }}^{0}\left(\theta_{2}\right)$ are the backscatter coefficients measured at $\theta_{1}$ and $\theta_{2}$, respectively, and:

$$
A=\frac{\sigma_{\mathrm{hh}}^{0}\left(\theta_{1}\right) \times \sin ^{4.117}\left(\theta_{1}\right) \times \cos ^{1.5}\left(\theta_{2}\right)}{\sigma_{\mathrm{hh}}^{0}\left(\theta_{2}\right) \times \sin ^{4.117}\left(\theta_{2}\right) \times \cos ^{1.5}\left(\theta_{1}\right)}
$$

The OM and GOM are not invertible in this manner. For these models, the numerical iterative Newton-Raphson method (Ortega and Rheinboldt, 1970) was used in the retrieval algorithm to solve the inverse problem.

In this regards, the variable matrices (the unknown variables) are $\mathbf{s}$ and $\boldsymbol{\varepsilon}_{\mathrm{r}}$ for OM and $\mathbf{s}, \boldsymbol{\varepsilon}_{\mathrm{r}}$, and $\boldsymbol{\ell}$ for GOM. The known parameters in the model are the backscatter coefficients at two or three different incidence angles. The algorithm can be summarized as follows:

Step 1. Presentations of the zeroed functions $\left(f_{i}\right)$ are issued by using GOM and OM based on the multi-angular approach. For example, these functions for $\mathrm{OM}$ are:

$$
\begin{aligned}
& f_{1}=\sigma_{\mathrm{hh}}^{0}\left(\theta_{1}\right)-g \sqrt{p} \cos ^{3} \theta_{1}\left[\Gamma_{\mathrm{v}}\left(\theta_{1}\right)+\Gamma_{\mathrm{h}}\left(\theta_{1}\right)\right]=0 \\
& f_{2}=\sigma_{\mathrm{hh}}^{0}\left(\theta_{2}\right)-g \sqrt{p} \cos ^{3} \theta_{2}\left[\Gamma_{\mathrm{v}}\left(\theta_{2}\right)+\Gamma_{\mathrm{h}}\left(\theta_{2}\right)\right]=0
\end{aligned}
$$

( $p$ and $g$ functions are already explained in Eq. 2). 


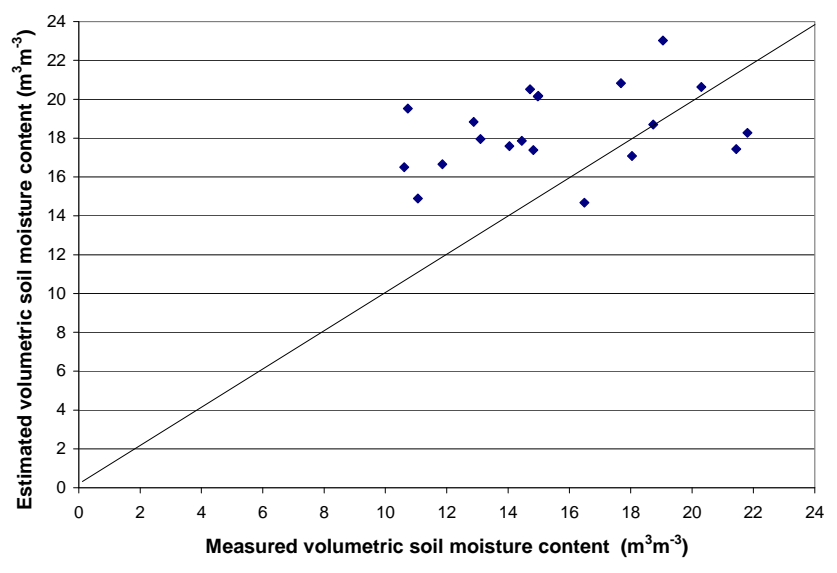

Fig. 3. Scatter plot of volumetric soil moisture content measured and estimated by MDM.

Step 2. Computation of the error matrix based on an initial guess of the variables $\left(\varepsilon_{\mathrm{r}}\right.$ and $\mathbf{s}$ for $\mathrm{OM} ; \boldsymbol{\varepsilon}_{\mathrm{r}}, \mathbf{s}$, and $\boldsymbol{\ell}$ for GOM).

Step 3. Computation of the matrix $\boldsymbol{\alpha}_{i j}$, which is the relation between the backscatter coefficient and the soil surface parameters. Equations (8) and (9) present this matrix for OM and GOM respectively:

for OM $\boldsymbol{\alpha}=\left[\begin{array}{ll}\frac{\partial f_{1}}{\partial s} & \frac{\partial f_{1}}{\partial \varepsilon_{\mathrm{r}}} \\ \frac{\partial f_{2}}{\partial s} & \frac{\partial f_{2}}{\partial \varepsilon_{\mathrm{r}}}\end{array}\right]$

for GOM $\quad \boldsymbol{\alpha}=\left[\begin{array}{lll}\frac{\partial f_{1}}{\partial s} & \frac{\partial f_{1}}{\partial \varepsilon_{\mathrm{r}}} & \frac{\partial f_{1}}{\partial \ell} \\ \frac{\partial f_{2}}{\partial s} & \frac{\partial f_{2}}{\partial \varepsilon_{\mathrm{r}}} & \frac{\partial f_{2}}{\partial \ell} \\ \frac{\partial f_{3}}{\partial s} & \frac{\partial f_{3}}{\partial \varepsilon_{\mathrm{r}}} & \frac{\partial f_{3}}{\partial \ell}\end{array}\right]$

Step 4. Calculation of the error $\left(\delta x_{j}\right)$ in the estimation of land surface properties.

Step 5. Correction of the error in the estimation of soil surface parameters.

Step 6. Through 5 are repeated until convergence is reached; that is, $\delta=10^{-5}$ for this case.

\subsection{Evaluation of the results}

Evaluation of errors requires comparisons between predicted and measured surface parameters. All comparisons between measured in-situ and predicted surface parameters obtained by RADARSAT-1 images are presented on an even basis for rms heights and surface dielectric constants (separately). They are carried out using the coefficient of performance $C P^{\prime}$ A (James and Burgess, 1982):

$C P^{\prime}{ }_{\mathrm{A}}=\sum_{i=1}^{n}(S(i)-O(i))^{2} / \sum_{i=1}^{n}\left(O(i)-O_{\mathrm{avg}}\right)^{2}$

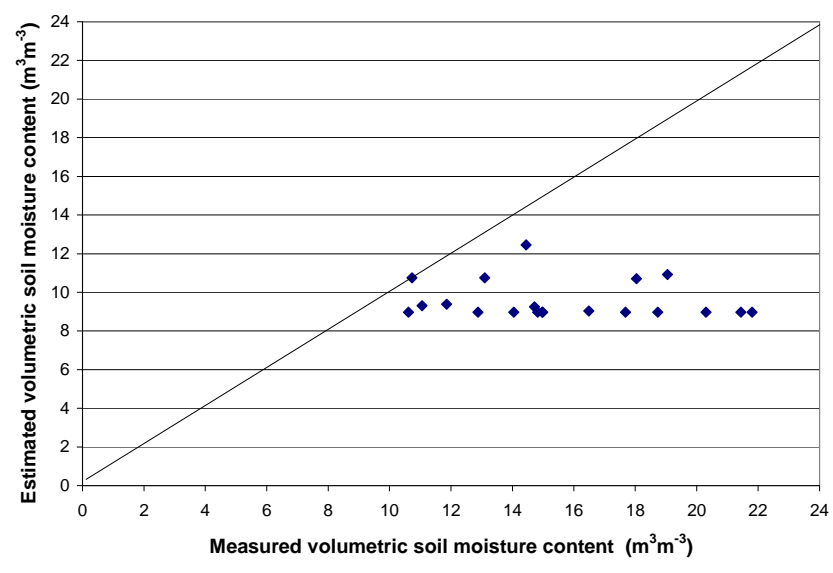

Fig. 4. Scatter plot of volumetric soil moisture contentmeasured and estimated by OM.

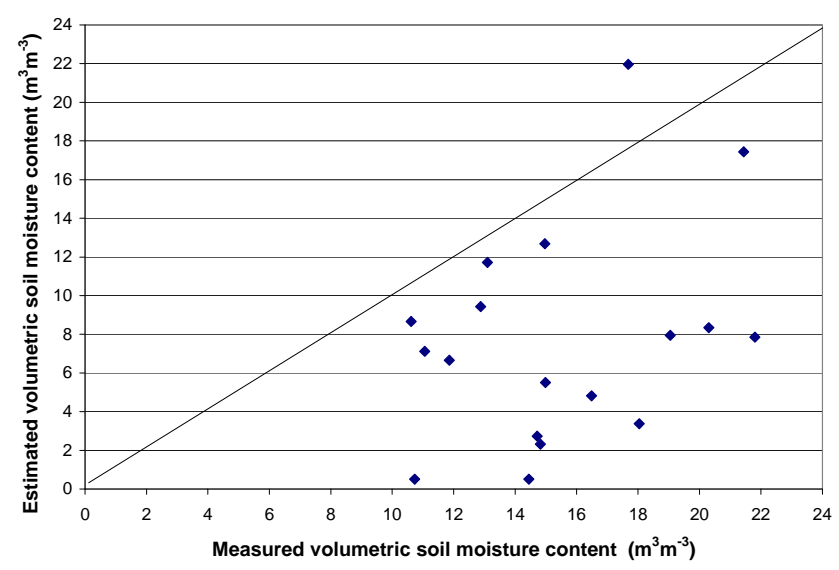

Fig. 5. Scatter plot of volumetric soil moisture contentmeasured and estimated by GOM.

where $O(i)$ is the $i$-th observed parameter, $O_{\text {avg }}$ is the mean value of the observed parameter, $S(i)$ is the $i$-th predicted parameter using radar images, and $n$ is the total number of events. The coefficient of performance approaches zero as observed and predicted values get closer. This coefficient can demonstrate the efficiency of each model for estimating surface parameters. In this study, the mean total absolute error for the results of each model is also calculated.

\section{Results and discussion}

Figures 3 to 8 present a comparison between the values of surface parameters estimated from the inversion of radar data and those measured in-situ. For rms height, the results with minimum error are given by GOM with a mean absolute error of $1.12 \mathrm{~cm}$ followed by MDM (with a mean error equal to $1.23 \mathrm{~cm}$ ) and $\mathrm{OM}$ (with a mean error equal to $2.08 \mathrm{~cm}$ ). However, MDM definitely has the best estimation for the 


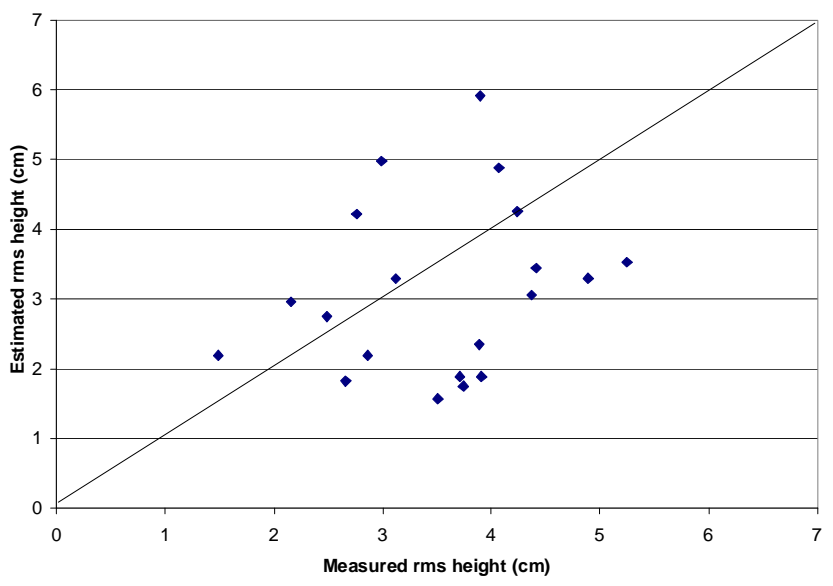

Fig. 6. Scatter plot of rms height measured and estimated by MDM.

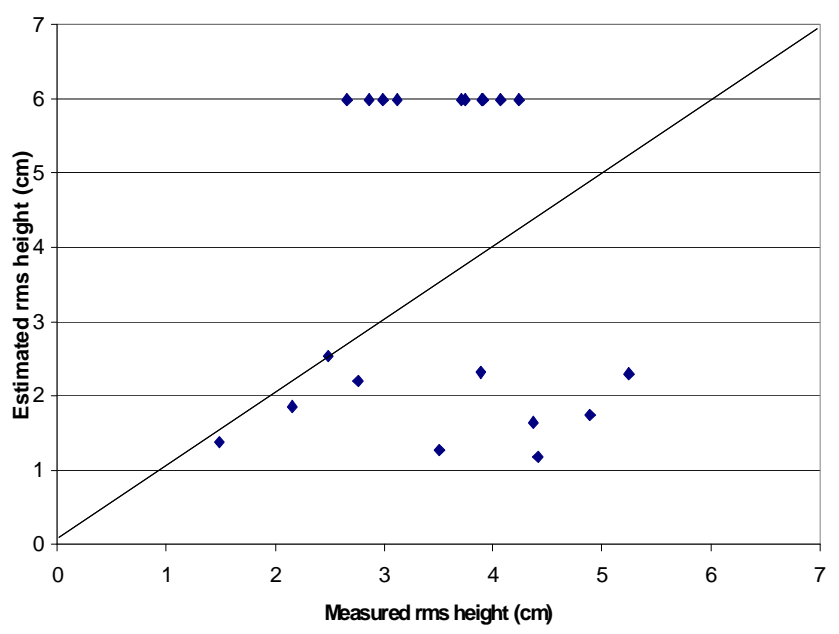

Fig. 7. Scatter plot of rms height measured and estimated by OM.

dielectric constant and soil moisture content with an error equal to 2.46 - equal to $3.88\left(\mathrm{~m}^{3} \mathrm{~m}^{-3}\right)$ in volumetric soil moisture - followed by OM with an error equal to 3.35 equal to $6.03\left(\mathrm{~m}^{3} \mathrm{~m}^{-3}\right)$ in volumetric soil moisture - and GOM with an error equal to $4.59-$ equal to $8.72\left(\mathrm{~m}^{3} \mathrm{~m}^{-3}\right)$ in volumetric soil moisture. As previously explained, the coefficient of performance $\left(C P_{\mathrm{A}}^{\prime}\right)$ was also used to compare these results. Table 1 presents the values of this coefficient. These results show that the inversion of MDM yields the best results for estimating soil surface parameters.

For MDM and OM, estimation of the dielectric constant is more exact than estimation of rms height. In contrast, the RMS height estimated by GOM is more exact. For GOM, total values of $C P^{\prime}{ }_{\mathrm{A}}$ for the dielectric constant are greater than those for rms height (Table 1). This sensitivity to roughness may be explained by the behavior of GOM. According to this model, the statistical variation in surface roughness is characterized by the RMS height, correlation length, and correlation function represented by the rms slope $(\mathrm{m})$ in

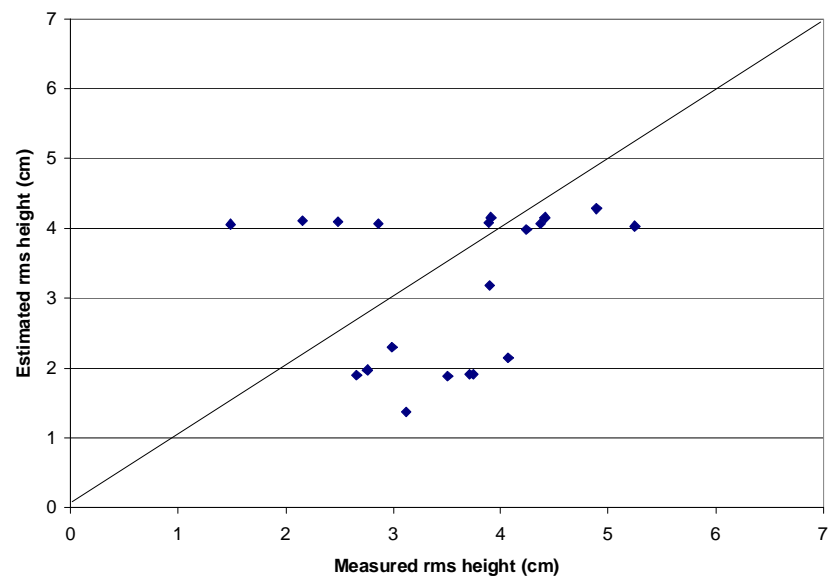

Fig. 8. Scatter plot of rms height measured and estimated by GOM.

Table 1. Mean absolute error and coefficient of performance $\left(\mathrm{CP}_{\mathrm{A}}^{\prime}\right)$ for surface parameters obtained by inversion approach.

\begin{tabular}{|c|c|c|c|c|c|c|}
\hline \multirow[t]{2}{*}{ Models } & \multicolumn{3}{|c|}{ Errors } & \multicolumn{3}{|c|}{$\mathrm{CP}_{\mathrm{A}}^{\prime}$} \\
\hline & $\begin{array}{l}\text { rms } \\
\text { height } \\
(\mathrm{cm})\end{array}$ & $\begin{array}{c}\text { Dielectric } \\
\text { constant }\end{array}$ & $\begin{array}{c}\text { Soil } \\
\text { moisture } \\
\text { content } \\
\left(\mathrm{m}^{3} \mathrm{~m}^{-3}\right)\end{array}$ & $\begin{array}{c}\text { rms } \\
\text { height }\end{array}$ & $\begin{array}{c}\text { Dielectric } \\
\text { constant }\end{array}$ & Total \\
\hline MDM & 1.23 & 2.46 & 3.88 & 2.26 & 1.7 & 1.98 \\
\hline GOM & 1.12 & 4.59 & 8.72 & 2.03 & 6.28 & 4.16 \\
\hline $\mathrm{OM}$ & 2.08 & 3.35 & 6.03 & 6.30 & 3.59 & 4.95 \\
\hline
\end{tabular}

Eq. (1). Therefore, the accuracy of the roughness estimation also depends on estimation of the correlation length. However, in MDM and OM, roughness is characterized only by rms height.

This study presents an approach to estimate surface parameters derived from SAR satellite data with acceptance errors calculated by comparing ground truth and estimated soil surface parameters. However, there are still errors in the estimation of soil surface parameters. Further investigations are required to understand this limitation, but several possibilities can already be suggested:

- Failure of the models to present a real relationship between radar signal properties and target parameters. Unfortunately, none of the backscatter models provides results in good agreement with experimental observations for all polarization configurations over a wide range of incident angles, even when confined to the presumed validity range (Henderson and Lewis, 1998; Baghdadi et al., 2004; Leconte et al., 2004; Moran et al., 2004). 


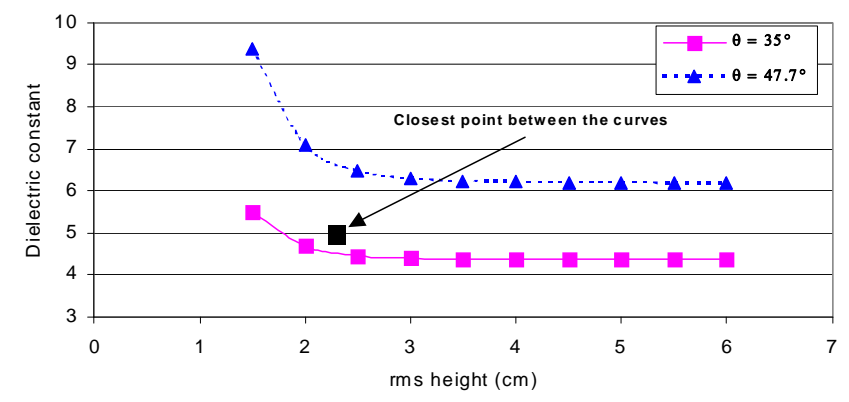

Fig. 9. Variation of the dielectric constant as a function of rms height for two different.

- Behavior of the models in the multi-angular approach context to find an exact solution. Consider the case of two dimensions to simultaneously solve:

$$
\left\{\begin{array}{l}
f 1: f_{\theta_{1}, \sigma^{0}}(\varepsilon, s)=0 \\
f 2: f_{\theta_{2}, \sigma^{0}}(\varepsilon, s)=0
\end{array}\right.
$$

An example of this case is presented by Eqs. (7a) and (7b) for OM. Each of the functions has zero regions where the function signs reverse (i.e. change positive to negative sign). Unfortunately, the functions $f_{1}$ and $f_{2}$ are not co-dependent according to the model behavior. Figure 9 shows the curves $\varepsilon$ vs. $s$ for parcel no $120\left(\sigma_{1}^{0}=-10.07 \mathrm{~dB}\right.$ and $\sigma_{2}^{0}=10.77 \mathrm{~dB}$ for $\theta_{1}=35^{\circ}$ and $\theta_{2}=47.4^{\circ}$, respectively) simulated by $\mathrm{OM}$ as an example of this situation. The solution obtained with these data was that the coordinate $s=2.32 \mathrm{~cm}$ and $\varepsilon=5$ was the closest point (minimum Euclidean distance) between the two curves. Therefore, the algorithm cannot properly solve the problem. This result was also observed in some cases in the inversion with GOM. Figure 10 shows the same curves simulated by MDM. These curves intersect exactly at $s=3.25 \mathrm{~cm}$ and $\varepsilon=11.75$, which is the exact solution of the system of equations.

- Incompatibility between ground measurements and estimated parameters. The ground data for each parcel are issued by some point measurements, and the mean is presented as rms height and dielectric constant of the parcel. This result was also reported by Lehrsch et al. (1988) and Bryant et al. (2007). Bryant et al. (2007) stated that measurement accuracy is the limiting factor in the accuracy of the soil moisture predictions for many cases. The accuracy of the in-situ measurements can be divided into three factors: (1) horizontal resolution, (2) vertical resolution, and (3) human-based error during digitization (Verhoest et al., 2008).

Bryant et al. (2007) evaluated the effect of averaging soil roughness parameters from a different

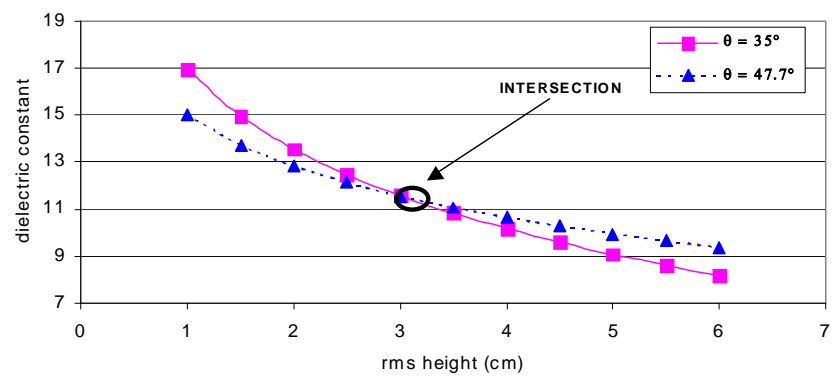

Fig. 10. Variation of the dielectric constant as a function of rms height for two different.

number of profiles on the soil surface parameters retrieval. These data revealed differences in volumetric soil moisture reaching up to $3.6 \%$ when comparing retrievals obtained with roughness parameters determined from 10 and 20 profiles.

Moreover, Álvarez-Mozos et al. (2009) investigated the spatial variability of roughness at the field scale and the impact on soil moisture retrieval for different fields. The conclusions of this study were the accuracy of the retrieved soil moisture depends on the variability of roughness parameters and in-field measurements.

In this study, the number of measurements enough to calculate an accurate mean value respects the recommendation presented by Baghdadi et al. (2008).

- Influence of tillage direction and look direction. The orientation of mechanical tillage, which can be related to roughness measurements, has an influence on backscattering signals (Remond et al., 1999; Smyth et al., 2000; Zhixiong et al., 2005). However, the backscatter models do not enable the simulation of this influence directly. Also, the use of images acquired at different orbits (ascending and descending) is sometimes inevitable in temporal studies with SAR data. The look direction accounted for a $1.5 \mathrm{~dB}$ difference in $\sigma^{0}$ for ERS-1 images by Gauthier et al. (1998). Smyth et al. (2000) obtained a maximum $2 \mathrm{~dB}$ difference in $\sigma^{0}$ for RADARSAT-1.

- Influence of speckle and climatic conditions on radar signals. Discussion of these problems is not the aim of this paper. However, these phenomena can produce some errors when calculating backscatter coefficients from satellite images.

Additionally, there is an important limitation in operational use of the multi-angular approach. Acquisition conditions for multi-angular RADARSAT, Envisat, and PALSARALOS data can often imply that the images were collected 


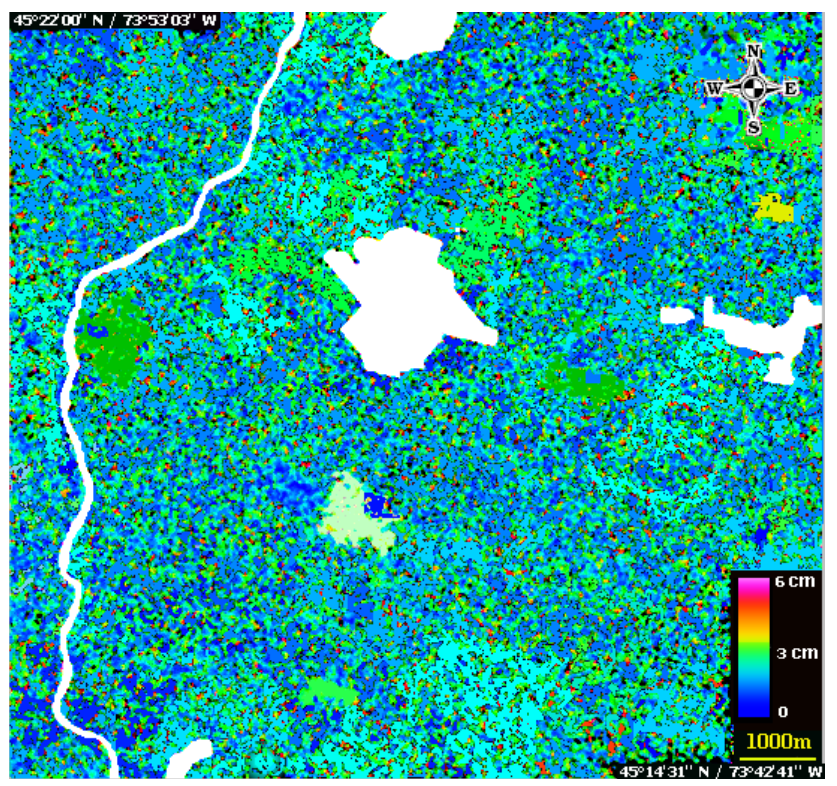

Fig. 11. rms height map at pixel scale.

several days apart, which indicates that the soil moisture and roughness might change between the two acquisition dates (e.g., rain, strong evaporation, ploughing). In the case of RADARSAT-1, this interval depends on the selection mode of data acquisition and can range from one to three days. However, the interval may be longer in some cases because of the other acquisition orders.

This situation should be improved with multi-sensor approaches, such as a combination of RADARSAT-1, RADARSAT-2, and ENVISAT images. In this regard, a set of RADARSAT- 1 and ENVISAT can be combined with an interval of 4 to $9 \mathrm{~h}$. In addition, the combination of multiangular, multi-polarization, or multi-frequency can be considered. However, this limitation is less important in regions with stable weather, such as arid or semi-arid regions, which typically experience no significant changes in soil surface condition.

\section{Surface parameter mapping}

The inversion algorithm using the MDM model was applied to two RADARSAT-1 images of the watershed under study. Two key points should be noted: (1) forest and urban areas are masked on the maps, and (2) the humidity maps are presented in terms of volumetric soil moisture $\left(\mathrm{m}^{3} \mathrm{~m}^{-3}\right)$ obtained by inverting the empirical model of the dielectric constant developed by Halikainen et al. (1985). This application was performed at two different scales: pixel scale and homogeneous zone scale. At pixel scale (Figs. 11 and 12), the inversion was applied directly on the two images pixel by pixel. The speckle in the images was reduced using Lee filtering (Lee, 1981). Due to field observation and ground truth

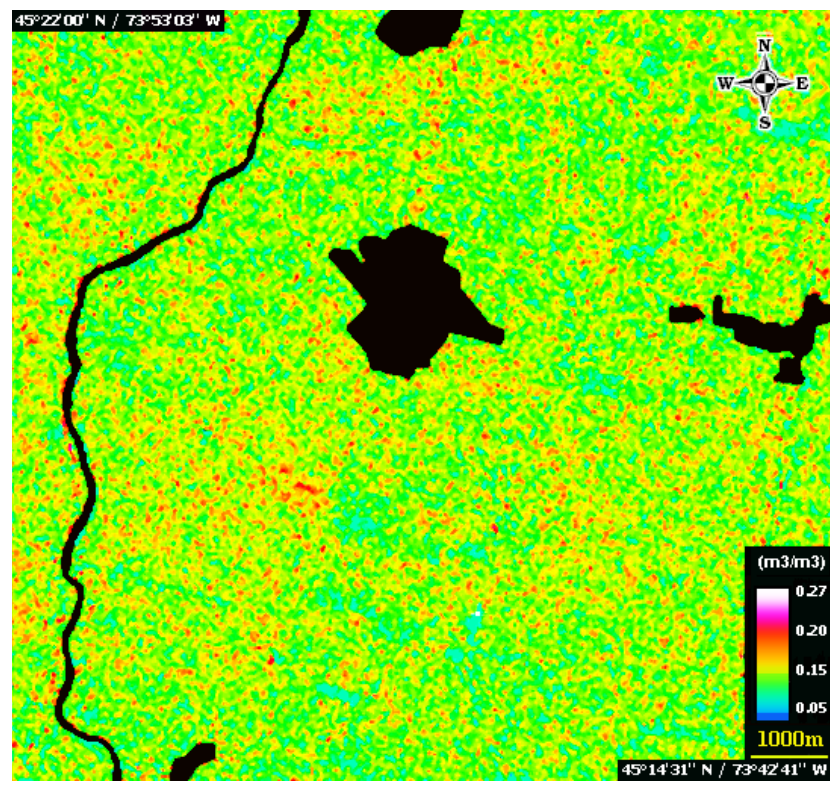

Fig. 12. Volumetric humidity map at pixel scale.

data, the pixel scale maps are more accurate for the spatial distribution of soil surface parameters. However, the pixel values vary and not tractable for use, and therefore, the surface parameter distribution over the watershed is difficult to determine. The homogeneous zone scale was utilized to reduce this problem. Each homogeneous zone on a radar image presents a minimal variance in the backscatter coefficients. Furthermore, the physical characteristics of the soil surface are almost the same within the homogeneous zone. This type of presentation allows for a general view of surface parameter distribution (Figs. 13 and 14).

As shown in Fig. 15, creating a homogeneous zone is comprised of four steps:

1. Improving the image contrast: contrast is only to provide better viewing of the images and does not modify the pixel values. This step provides a better view of the images for manual digitization (step 3).

2. Noise reduction. This step is performed using despeckle filters. Generally, the adaptive filters, such as gamma, Lee or Frost filters, reduce noise notably. In this study, the Lee filter and a low-pass filter (mean filter) were tested. As expected, the Lee filter reduced speckle better than the low-pass filter, but it modified the pixel values and changed the final results. In contrast, the low-pass filter reduced noise less than the Lee filter, but the pixel values did not change significantly. This fact was evaluated by comparing the ground truth measurement and soil surface estimated values obtained from the images. The algorithm was applied on filtered images, and the results were compared with control points from in-situ measurements. In general, 


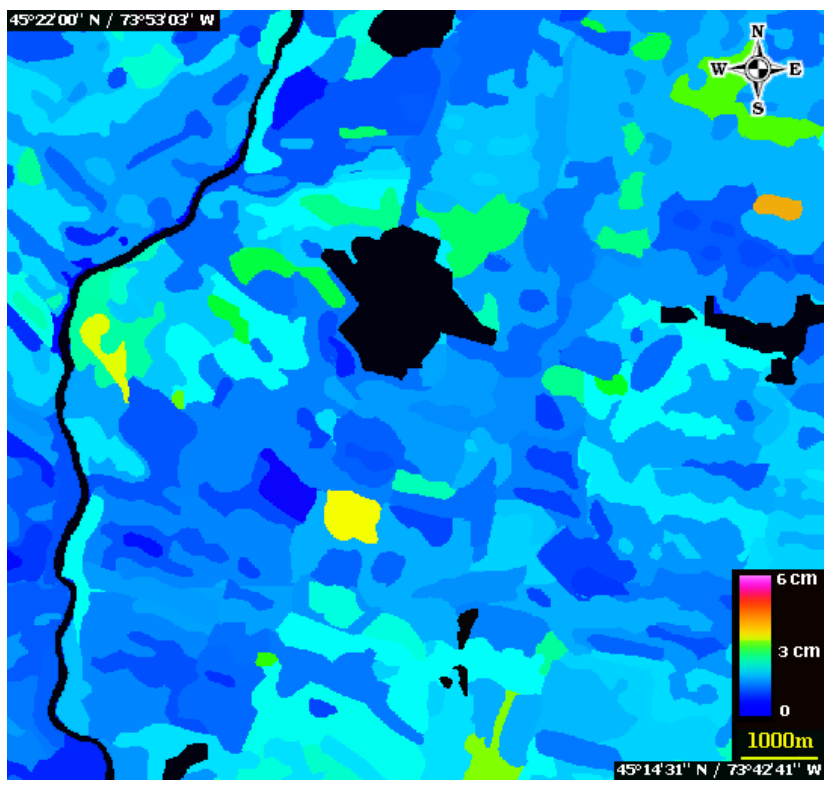

Fig. 13. rms height map in homogeneous zone scale.

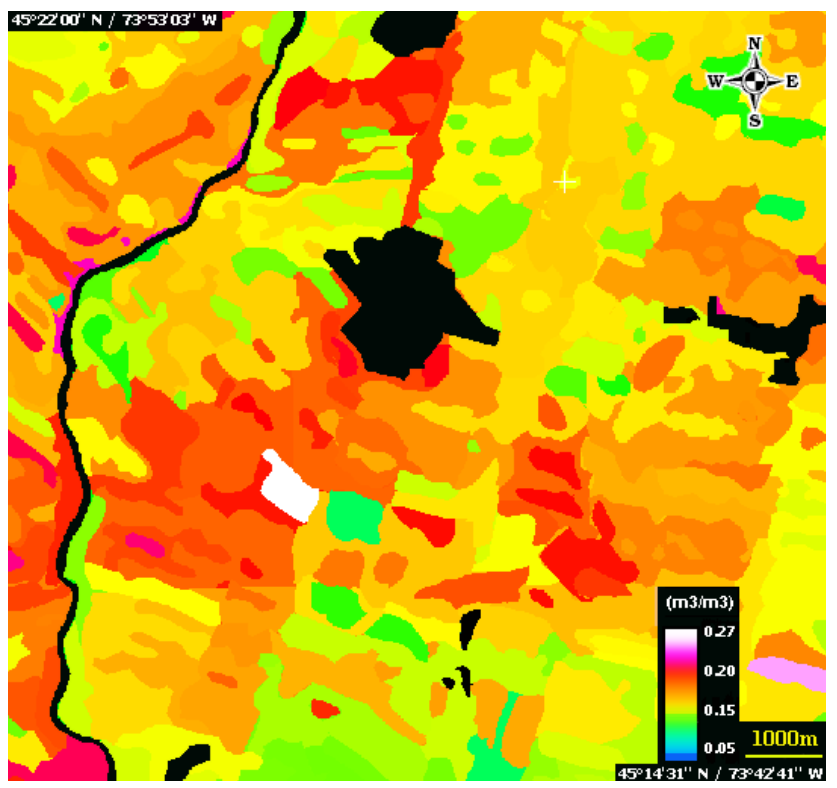

Fig. 14. Volumetric humidity map at homogeneous zone scale.

the final results of the images filtered by low-pass filter have the lowest error.

However, the final results (homogeneous zone maps) were approximately the same. Therefore, the best filter should be chosen in each case. For this study, the low-pass filter was the best option.

3. Edge detection of homogeneous zones. In this step, Sobel filters were used to delimit the homogeneous zones based on the minimal variance of $\sigma^{0}$ in each zone

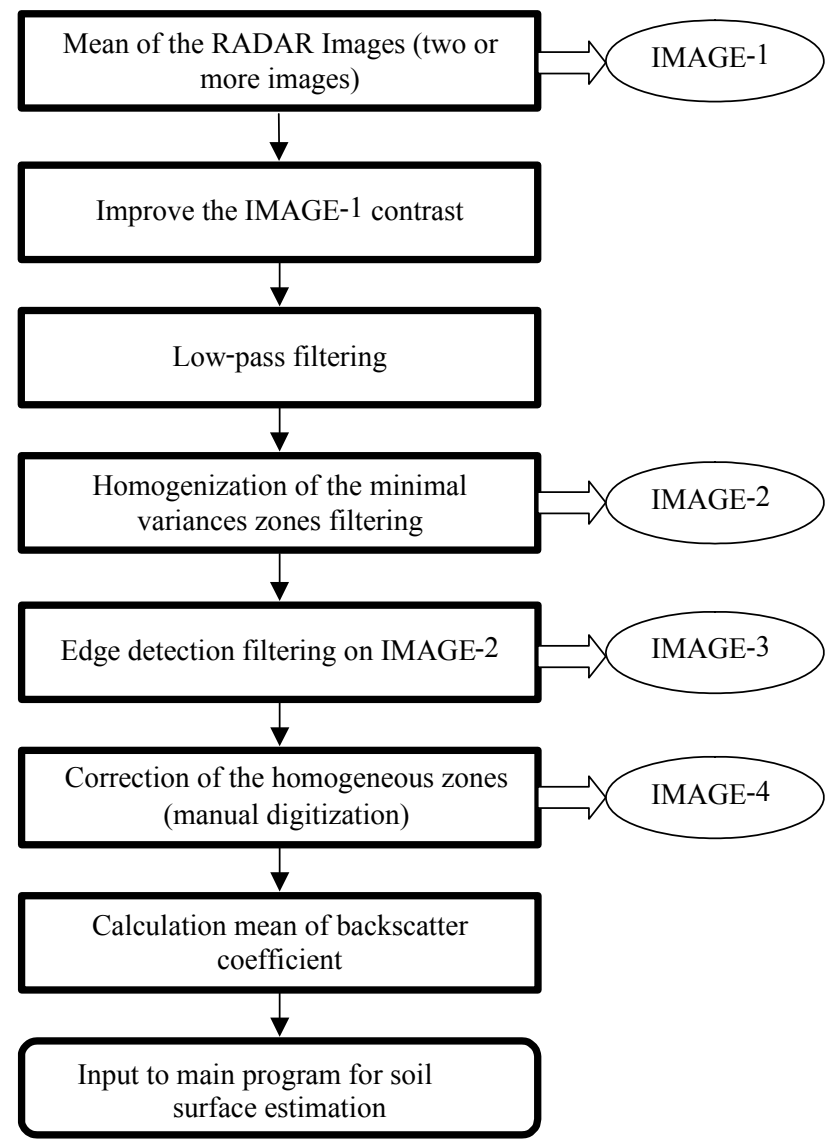

Fig. 15. Flowchart of homogeneous zone calculation.

(Angles, 2001), and the edge of each zone was detected using an edge detection filter. For a few zones, the edge polygon was not correctly closed. This problem was corrected manually.

4. Averaging. In the last step, the average of the $\sigma^{0} \mathrm{~s}$ in each zone was calculated and presented as the homogeneous zone $\sigma^{0}$ value.

\section{Conclusions}

This work has demonstrated the possibility of using the multi-angular approach to derive soil moisture and surface roughness from a pair of RADARSAT-1 images.

The proposed algorithm were presented in five phases: (1) image pre-processing and co-registration, (2) extraction of backscattering coefficients, (3) choosing the appropriate backscattering model, (4) inversion of backscattering models (analytically or numerically) for calculation of soil surface parameters, and (5) presenting the calculated parameters.

Despite the generation of some errors, this estimation derived from SAR satellite data is a potentially useful tool for 
estimating soil surface roughness and moisture over extended areas. The source of errors can be expressed either by some essential averaging, the behavior of the backscattering models, or the incompatibility of the ground measurements and results obtained using satellite images. However, the results presented herein demonstrated that the multi-angular approach, it is possible to obtain the acceptable results for the overall watershed area.

The Modified Dubois Model (MDM) developed for agricultural sites in Quebec was used to minimize the influence of backscatter models and presented minimal errors. This result was obtained by comparing the same results calculated by GOM, MDM, and OM.

From an application point of view, the final products of this investigation are soil surface parameter maps. These maps were produced at two different scales that can serve for many applications, such as hydrological models and agricultural or environmental management. For example, the pixel scale maps of moisture and roughness can readily be used in hydrological models based on pixel-like units, such as AGNPS (Young et al., 1987) or ANSWERS (Beasley et al., 1980). However, the homogeneous zone maps present the soil surface distribution over a large area and can be used in agricultural or hydrological management at the subcatchment scale by hydrological response units, such as the SWAT (Soil and Water Assessment Tool) model (Arnold et al., 1993). However, there is still a major limitation to this approach for an operational use in hydrology. Acquisition conditions for multi-angular RADARSAT- 1 data can often imply several days between collections of the two images. Soil moisture and roughness can change between the two dates (e.g., rain, strong evaporation, ploughing). However, this situation should improve with RADARSAT-2 or multisensor approaches, such as a combination of RADARSAT-1 and ENVISAT images.

Acknowledgements. This study was led by Ferdinand J. Bonn (1943-2006), who was an outstanding researcher, a terrific teacher, and simply put, a wonderful man. Also, this work was partially supported by FCAR (Action Concertée Radarsat) and NSERC. The authors want to thank all CARTEL colleagues, especially P. Gagnon, G. Bennié, R. Magagi, and D. C. He for their help and editing assistance.

Edited by: N. Verhoest

\section{References}

Álvarez-Mozos, J., Verhoest, N. E. C., Larrañaga, A., Casalí, J., and González-Audícana, M.: Influence of surface roughness spatial variability and temporal dynamics on the retrieval of soil moisture from SAR observations, Sensors, 9, 463-489, 2009.

Angles, J.: Séparation de l'humidité et de la rugosité dans le signal retrodiffusé des images RSO selon une approche multi-angle, Mémoire de Maîtrise, Dép. de géographie et télédétection, Université de Sherbrooke, Canada, 82 pp., 2001.
Arnold, J. G. Allen, P. M., and Bernhardt, G.: A comprehensive surface-groundwater flow model, J. Hydrol., 142, 47-69, 1993.

Baghdadi, N., Gaultier, S., and King, C.: Retrieving surface roughness and soil moisture from synthetic aperture radar (SAR) data using neural networks, Can. J. Remote Sens., 28, 701-711, 2002.

Baghdadi, N., Gherboudj, I., Zribi, M., Sahebi, M., King, C., and Bonn, F.: Semi-empirical calibration of the IEM backscattering model using radar images and moisture and roughness field measurements, Int. J. Remote Sens., 25, 3593-3623, 2004.

Baghdadi, N., Holah, N., and Zribi, M.: Soil moisture estimation using multi-incidence and multipolarization ASAR SAR data, Int. J. Remote Sens., 27, 1907-1920, 2006.

Baghdadi, N., Cerdan, O., Zribi, M., Auzet, V., Darboux, F., El Hajj, M., and Bou Kheir, R.: Operational performance of current synthetic aperture radar sensors in mapping soil surface characteristics in agricultural environments: application to hydrological and erosion modelling, Hydrol. Process., 22, 9-20, 2008.

Beasley, D. B., Huggins, L. F., and Monke, E. J.: ANSWERS: A model for watershed planning, T. Am. Soc. Agr. Eng., 23(4), 938-944, 1980.

Beaulieu, N., Leclerc, G., and Moisan, Y.: Détermination de la rugosité de surface par des méthodes accessibles, Can. J. Remote Sens., 21, 198-203, 1995.

Benallegue, M., Taconet, O., Vidal-Madjar, D., and Normand, A.: The use of radar backscattering signals for measuring soil moisture and surface roughness, Remote Sens. Environ., 53, 61-68, 1998.

Bryant, R., Moran, M. S., Thoma, D. P., Holifield Collins, C. D., Skirvin, S., Rahman, M., Slocum, K., Starks, P., Bosch, D., and González Dugo, M. P.: Measuring surface roughness height to parameterize radar backscatter models for retrieval of surface soil moisture, IEEE Geosci. Remote Sens. Lett., 4, 137-141, 2007.

Chanzy, A., King, C., Prévot, L., and Remond, A.: Comparison of ERS and RADARSAT measurements on bare soils, first results, Second Int. Workshop on Retrieval of Bio-\& Geo-physical Parameters from SAR Data, ESTEC, The Netherlands, 471-477, 1998.

Colpitts, B. G.: The integral equation model and surface roughness signatures in soil moisture and tillage type determination, IEEE T. Geosci. Remote, 36, 833-837, 1998.

Delta Devices Ltd.: Thetaprobe soil moisture sensor, User manual, M11-UM-2, Delta Devices Ltd, UK, 18 pp., 1996.

Dobson, M. C. and Ulaby, F. T.: Active microwave soil moisture research, IEEE T. Geosci. Remote, 24(1), 23-36, 1986a.

Dobson, M. C. and Ulaby, F. T.: Preliminary evaluation of the SIRB response to soil moisture, surface roughness, and crop canopy cover, IEEE T. Geosci. Remote, GE-24(4), 517-526, 1986b.

Dubois, P. C., van Zyl, J., and Engman, T.: Measuring soil moisture with imaging radars, IEEE T. Geosci. Remote, 33(4), 915-926, 1995.

Engman, E. T. and Wang, J. R.: Evaluation Roughness Models of Radar Backscatter, IEEE T. Geosci. Remote, GE-25(6), 709713, 1987.

Fung, A. K.: Microwave scattering and emission models and their applications, Norwood, Artech House, 573 pp., 1994.

Fung, A. K. and Chen, K. S.: Dependence of the surface backscattering coefficients on roughness, frequency and polarization states, Int. J. Remote Sens., 13(9), 1663-1680, 1992. 
Fung, A. K., Dawson, M. S., Chen, K. S., Hsu, A. Y., Engman, E. T., O'Neill, P. E., and Wang, J.: A modified IEM model for scattering from soil surfaces with application to soil moisture sensing, in: Proceedings of the International Geoscience and Remote Sensing Symposium (IGARSS'96), Lincoln, Nebrasca, USA, 1297-1299, 1996.

Gauthier, Y., Bernier, M., and Fortin, J. P.: Aspect and incidence angle sensivity in ERS-1 SAR data, Int. J. Remote Sens., 19(9), 2001-2006, 1998.

Halikainen, M. T., Ulaby, F. T., Dobson, M. C., El-Rays, M. A., and Wu, L.: Microwave dielectric behavior of wet soil - Part I - Empirical models and experimental observations, IEEE T. Geosci. Elect., GE-23(1), 25-34, 1985.

Henderson, F. M. and Lewis, A. J.: Principles and applications of imaging radar, John Wiley \& Son Inc., 3rd edition, Chapter 8, 1074 pp., 1998.

James, L. D. and Burgess, S. J.: Selection, calibration and testing of hydrologic models, in: Hydrologic Modeling of Small Watersheds, edited by: Hann, C. T., Johnson, H. P., and Brakkensiek, D. L., ASAE, St. Joseph, Mich, 437-472, 1982.

Leconte, R., Brissette, F., Galarneau, M., and Rousselle, J.: Mapping near-surface soil moisture with RADARSAT-1 synthetic aperture radar data, Water Resour. Res., 40, 1-13, 2004.

Lee, J. S.: Refined filtering of image noise using local statistics, Comput. Vision. Graph., 15, 380-389, 1981.

Lehrsch, G. A., Whisler, F. D., and Römkens, M. J. M.: Spatial variation of parameters describing soil surface roughness, Soil Sci. Soc. Am. J., 52, 311-319, 1988.

Mattia, F., Davidson, M. W. J., Le Toan, T., D’Haese, C. M. F., Verhoest, N. E. C., Gatti, A. M., and Borgeaud, M.: A comparison between soil roughness statistics used in surface scattering models derived from mechanical and laser profilers, IEEE T. Geosci. Remote, 41, 1659-1671, 2003.

Mattia, F., Satalino, G., Dente, L., and Pasquariello, G.: Using a priori information to improve soil moisture retrieval from ENVISAT ASAR AP data in semiarid regions, IEEE T. Geosci. Remote, 44, 900-912, 2006.

Moran, M. S., Peters-Lidard, C. D., Watts, J. M., and McElroy, S.: Estimating soil moisture at the watershed scale with satellitebased radar and land surface models, Can. J. Remote Sens., 30, 805-826, 2004.

Oh, Y., Sarabandi, K., and Ulaby, F. T.: An empirical model and inversion technique for radar scattering from bare soil surfaces, IEEE T. Geosci. Remote, 30(2), 370-381, 1992.

Ortega, J. M. and Rheinboldt, W. C.: Iterative solution of nonlinear equations in several variables, New York, Academic Press Inc., 572 pp., 1970.

Pasquariello, G., Satalino, G., Mattia, F., Casarano, D., Posa, F., Souyris, J. C., and Le Toan, T.: On the retrieval of soil moisture from SAR data over bare soils, in: Proceedings of the International Geoscience and Remote Sensing Symposium (IGARSS'97), Singapore, 1272-1274, 1997.

Prévot, L., Champion, I., and Guyot, G.: Estimating surface soil moisture and leaf area index of a Wheat Canopy Using a DualFrequency (C and X Bands) Scatterometer, Remote Sens. Environ., 46, 331-339, 1993.
Rahman, M. M., Moran, M. S., Thoma, D. P., Bryant, R., Holifield Collins, C. D., Jackson, T., Orr, B. J., and Tischler, M.: Mapping surface roughness and soil moisture using multi-angle radar imagery without ancillary data, Remote Sens. Environ., 112, 391402, 2008.

Remond, A., Beaudoin, A., and King C.: SAR imagery to estimate roughness parameters when modelling runoff risk, Int. J. Remote Sens., 20(13), 2613-2625, 1999.

Sahebi, M. R., Angles, J., and Bonn, F.: A multi-angular Radarsat based C-band backscattering model for estimation of bare soil surface roughness, Proceedings of the 23rd Canadian Symposium on Remote Sensing, 21-24 August, 2001, Ste-Foy, Canada, 865-871, 2001.

Sahebi, M. R., Angles, J., and Bonn, F.: A comparison of multipolarization and multi-angular approaches for estimating bare soil surface roughness from spaceborne radar data, Can. J. Remote Sens., 28(5), 641-652, 2002.

Shepard, N.: Extraction of beta nought and sigma nought from RADARSAT CDPF products, ALTRIX Systems, Ontario, Canada, Report No. AS97-5001, 12, 1998.

Smyth, J., Bonn, F., Hardy, S., Rémond, A., and Clément, P.: Potential retrieval of tillage direction as a runoff indicator using RADARSAT data, Remote Sensing in Hydrology 2000, AIHS Red book 267, 368-370, 2000.

Ulaby, F. T., Batlivala, P. P., and Dobson, M. C.: Microwave dependence on surface Roughness, soil moisture and soil texture: Part I - bare soil, IEEE T. Geosci. Elect., 16(4), 286-295, 1978.

Ulaby, F. T., Moore, R. K., and Fung, A. K.: Microwave remote sensing active and passive, Vol. II, Radar Remote Sensing and Surface Scattering and Emission Theory, Artech House, Ann Arbor Ltd., 457-1064, 1982.

Ulaby, F. T., Dubois, P. C., and van Zyl, J.: Radar mapping of surface soil moisture, J. Hydrol., 184, 57-84, 1996.

Verhoest N. E. C., Lievens, H., Wagner, W., Álvarez-Mozos, J., Moran, S., and Mattia, F.: On the soil roughness parameterization problem in soil moisture retrieval of bare surfaces from Synthetic Aperture Radar, Sensors, 8, 4213-4248, 2008.

Wagner, W., Blöschl, G., Pampaloni, P., Calvet, J.-C., Bizzarri, B., Wigneron, J.-P., and Kerr, Y.: Operational readiness of microwave remote sensing of soil moisture for hydrologic applications, Nord. Hydrol., 38, 1-20, 2007.

Young, R. A., Onstad, C. A., Bosch, D. D., and Anderson, W. P.: Agricultural nonpoint-source pollution model (AGNPS) I and II Model documentation, St. Paul, Minn, Pollution Control Agency, Washington, DC, USDA-ARS, 77, 1987.

Zhixiong, L., Nan, C., Perdok, U. D., and Hoogmoed, W. B.: Characterisation of Soil Profile Roughness, Biosyst. Eng., 91, 369377, 2005

Zribi, M. and Dechambre, M.: A new empirical model to retrieve soil moisture and roughness from radar data, Remote Sens. Environ., 84, 42-52, 2002. 